\title{
АИСКУССИИ, ОБСУЖАЕНИЯ
}

УДК $551.24(234.9)$

DOI: 10.23671/VNC.2014.4.55487

\section{ОБ ЭВОЛЮЦИИ И СОВРЕМЕННОМ СОСТОЯНИИ ПРЕДСТАВЛЕНИЙ НЕКОТОРЫХ ГЛЯЦИОЛОГОВ О КАТАСТРОФЕ НА ЛЕДНИКЕ КОЛКА И В ГЕНАЛДОНСКОМ УЩЕЛЬЕ 20 СЕНТЯБРЯ 2002 Г. СПИСОК Л.В. ДЕСИНОВА: ФАКТЫ И АРТЕФАКТЫ}

\author{
() 2014 М.Г. Бергер${ }^{1,2}$, д.г.-м.н., профр.; В.Б. Заалишвили², д.ф.-м.н., профр. \\ ${ }^{1}$ Северо-Кавказский инновационный центр «Устойчивое развитие горных \\ территорий»; 'Центр геофизических исследований ВНЦ РАН и РСО-А, Россия, \\ 362002, г. Владикавказ, ул. Маркова 93а. e-mail: berger7@rambler.ru; \\ cgi_ras@mail.ru.
}

В статье рассмотрен список Л.В. Десинова, содержащий, по его утверждению, перечень фактов, характеризующих катастрофу на леднике Колка и в Геналдонском ущелье 20 сентября 2002 г. Приведены краткие комментарии к этим фактам. Показаны существенная (но только частичная) транссоормация и современное состояние представлений Л.В. Десинова о характере и причинах Колкинской катастрофы и дана оценка их обоснованности.

Ключевые слова: Ледник Колка, катастрофа 2002 г., факты, артефакты.

Дадим краткое определение: артефакт - выдаваемое за факт утверждение, не соответствующее действительности.

Факты - основа идентификации (диагностики) характера, сущности Колкинской катастрофы, необходимой для установления ее причин.

Существует весьма обширный, многочисленный и разнообразный комплекс фактов, характеризующих грандиозную природную катастрофу на леднике Колка и в Геналдонском ущелье 20 сентября 2002 г.

Нередко весьма различны генетическая интерпретация этих фактов и оценка заключенного в них смысла и их значения для познания и объяснения Колкинской катастрофы. Существенно различна и степень соответствия этих фактов действительности.

В данной статье мы ограничимся лишь далеко не полным списком таких фактов, приведенным Л.В. Десиновым [Десинов, 2014], и очень краткими комментариями к этому списку.

Используемая ниже нумерация соответствует нумерации, приведенной в списке Л.В. Десинова [Десинов, 2014].

1. По утверждению Л.В. Десинова [Десинов, 2014], об эволюции ледника Колка до его позиционирования в каньоне на выходе в долину р. Геналдон информация отсутствует. 
Это утверждение может рассматриваться как отказ от приведенной ранее [Десинов, 2004; и др.] весьма детальной информации об этой эволюции, оказавшейся, в частности, по данным космофотосъемки [Тутубалина и др., 2005], во многом необоснованной и ошибочной, и ставит под сомнение обоснованность некоторых сведений, приведенных в качестве фактов [Десинов, 2014].

На самом же деле имеется весьма значительная (хотя, конечно, далеко не полная) очень важная информация о состоянии и эволюции ледника в это время и Л.В. Десинов в последующей части своего списка неоднократно (хотя, к сожалению, далеко не в полной мере) приводит эту информацию (см. ниже).

2. В качестве «факта 2» Л.В. Десинов [Десинов, 2014] приводит высказывание К.П. Рототаева [Рототаев и др., 1983] о «турбулентно-вязком ледовом селе со значительным водосодержанием» и «селе турбулентно-жидкого типа» (еще до Скалистого хребта), очевидно, полагая, что именно таким был характер Колкинской катастрофы 2002 г.

По отношению к Колкинской катастрофе 2002 г. это заключение Л.В. Десинова не соответствует действительности и должно считаться одним из наиболее распространенных артефактов в данной области.

Такому заключению Л.В. Десинова противоречат характеризующие эту катастрофу многочисленные факты как приведенные Л.В. Десиновым [Десинов, 2014] (см. ниже), так и не приведенные им [Черноморец, 2005; Дробышев, 2012 и др.].

3. Под этим номером Л.В. Десинов [Десинов, 2014] приводит некоторые известные [Рототаев и др., 1983] сведения о леднике Колка, не определяющие, однако, характер и причины происходящих на леднике событий и, соответственно, не дающие оснований для их расшифровки.

4. Продолжая приведенную в предыдущем пункте информацию, Л.В. Десинов [Десинов, 2014] отмечает существование препятствия (левой береговой морены), которое «затрудняет движение льда и способно надолго задерживать его быстрое продвижение, провоцируя импульсный выброс после накопления большой критической порции льда» под воздействием «роста напряжений сдвигающих сил».

Но это не может привести к взрывному выбросу ледника, подобному его выбросу 20 сентября 2002 г., о котором далее пишет Л.В. Десинов, и, соответственно, не могло вызвать Колкинскую катастрофу в ее нынешнем понимании Л.В. Десиновым (при всей непоследовательности, противоречивости и в значительной мере ошибочности его понимания - см. ниже).

5. Вышеизложенное (пп. 3 и 4) в полной мере относится и к упоминаемым Л.В. Десиновым еще двум препятствиям, которые приходится преодолевать наступающему леднику Колка, - это «крутой поворот ущелья на $60^{\circ}$ » и «очень тесный поперечный профиль ущелья, в которое с трудом втискивается наступающий ледник».

6. «Как всякий карово-долинный ледник, Колка имеет переуглубленное ложе и поперечный уступ, способствующий накоплению на ложе большого объема воды» [Десинов, 2014].

Здесь Л.В. Десинов, очевидно, возвращается к своим прежним представлениям, согласно которым «решающая роль в катастрофическом характере последней подвижки ледника Колка принадлежит воде» [Десинов, 2004, с. 79].

Собственно говоря, в течение более десяти лет, прошедших со дня этой катастрофы, Л.В. Десинов никогда не отказывался от таких представлений, лишь в по- 
следние годы иногда эклектично дополняя их высказываниями о «взрывном характере» Колкинской катастрофы без раскрытия конкретной роли воды в механизме ее протекания.

7. «Тыловая область ледника Колка расположена в месте пересечения двух крупных разломов земной коры» [Десинов, 2014].

Это, действительно, очень важный факт для понимания избирательности проявления Колкинской катастрофы с учетом ее газодинамической природы. Не понимая, однако, значения данного факта для определения характера и причин Колкинской катастрофы, Л.В. Десинов никак не комментирует его и ограничивается лишь приведением следующего факта (п. 8).

8. «Обрушение висячих ледников и горных пород произошло только вдоль узкой полосы пересечения правого склона ледника Колка субмеридиональным разломом земной коры» [Десинов, 2014].

Именно вдоль этой полосы проявилась и наиболее явно выраженная газовая пред- и послекатастрофическая поствулканическая (фумарольная) деятельность.

Совершенно очевидно, что именно в этой разломной трещинно-разрывной зоне высокой проницаемости земной коры происходил и наиболее интенсивный сосредоточенный концентрированный прорыв высоконапорных глубинных поствулканических газов, сопровождавшийся мощным динамическим и термальным воздействием на ледники (в том числе на ледник Колка, а также висячие ледники северного склона г. Джимарайхох и ее восточных отрогов) и породы их скального основания.

9. «С 21 марта по 17 сентября (2002 г.) в Северной Осетии произошло 18 землетрясений с магнитудой более 1 балла. 14 июля и 25 августа сила толчков превысила 3 балла» [Десинов, 2014].

Этот факт и его значимость в плане подготовки Колкинской катастрофы Л.В. Десинов также оставляет без комментариев. Тем не менее, явно повышенная сейсмическая активность данного этапа, как можно думать, могла привести к усилению интенсивности протекания в данном районе процессов сейсмотектонического пульсационного нагнетания глубинных флюидов (в том числе поствулканических газов), в соответствии с известной дилатансной (дилатансионной) флюиднодиффузионной моделью [Файф и др., 1981, с. 350 и далее; и др.]. Это, естественно, ускоряло подготовку газодинамического выброса ледника Колка, приближало время его проявления.

10. «Горные породы и лед обрушились в тыловую область ледника с его правого склона задолго до катастрофы» [Десинов, 2014].

Обстоятельное рассмотрение данного вопроса, по которому все еще существуют различные мнения, недавно проведено в работе [Бергер, 2012в].

11. «До лета 2002 г. тыловая область ледника Колка была ровной без следов обвала льда и горных пород» [Десинов, 2014].

Так что до лета 2002 г. никаких внешних признаков нестабильности ледника Колка и подготовки его к пульсации еще не было. Другие данные на этот счет (геофизические, геохимические или иные) также неизвестны - соответствующие мониторинговые исследования не проводились. Не исключено, однако, что уже в начале лета 2002 г. существовали какие-то аномальные особенности геофизических и геохимических полей (например, изменения гидрогеодеформационного поля или эмиссии радона), отражавшие протекание глубинных процессов подготовки Кол- 
кинской катастрофы с учетом ее газодинамического характера и глубинного поствулканического генезиса огромного количества высоконапорных газов, воздействие которых на ледник вызвало эту катастрофу, но, безусловно, не ограничивалось лишь площадью ледника Колка.

12. «Обрушенные массы льда и горных пород в тыловой зоне ледника к началу сентября 2002 г. заполнили ее слоем высотой более 10 м. Следов перемещения этого материала за гребень правой (? - М. Б. $и$ В. 3.) береговой морены не наблюдалось. В самом начале этой морены она была экранирована упавшим льдом и обломками камней» [Десинов, 2014].

С учетом, в частности, приведенной Л.В. Десиновым иллюстрации к этому пункту, речь в данном случае идет, по-видимому, не о правой, а о левой береговой морене.

Приведенные факты свидетельствуют о том, что наблюдавшиеся после катастрофы крупные следы перемещения ледово-каменного материала за гребень этой морены имеют не обвальное или лавинное (как нередко полагают), а взрывное происхождение, являются, наряду с многими другими признаками, следами центробежного разлета ледово-каменного материала в эпицентре катастрофы и, соответственно, указывают на взрывной или взрывоподобный газодинамический характер Колкинской катастрофы. Об этом же свидетельствуют и все другие оставленные ею следы [Бергер, 2012б, г].

13. «В тыловой области ледника вдоль склона и рядом с правой береговой мореной к началу сентября 2002 г. возникли крупные трещины» [Десинов, 2014].

В генетическом и предвестниковом отношениях возникновение этих трещин может быть конвергентным и, соответственно, неоднозначно.

Несомненно, однако, что существование таких трещин благоприятствовало процессам дальнейшего разрушения и последующего выброса ледника, уменьшало затраты энергии на преодоление сил сцепления (смерзания) ледника с боковыми породами.

14. «27 и 28 августа 2002 г. с ледника Колка прекратился сток. К вечеру 28 августа ледник продуцировал селевой поток, который продвинулся по долине реки Геналдон на расстояние более 2 км. (Наблюдалось туристами - О. Неподоба). Такое же событие произошло в 1969 г. перед началом пульсации» [Десинов, 2014].

В 1969 г. такое событие произошло не перед началом пульсации, а в ходе ее проявления, в ходе уже начавшегося «бурного наступания» ледника Колка [Рототаев и др., 1983, с. 31]. Как документально засвидетельствовали материалы космофотосьемки [Тутубалина и др., 2005], в 2002 г. ни 27-28 августа, ни позднее, вплоть до самого момента выброса ледника 20 сентября, ничего подобного на леднике Колка не было. Имеющиеся материалы сейсмических наблюдений [Заалишвили, Мельков, 2008, 2012; Заалишвили, Харебов, 2008; Процесс схода..., 2009; Ледник Колка..., 2014] также не подтверждают представления Л.В. Десинова [Десинов, 2004, 2014] о поступательном продвижении фронтальной части языка ледника Колка до 16 часов 08 минут по среднегринвичскому времени, т. е. до начала пароксизмального катастрофического выброса ледника.

15. «13 августа 2002 г. фотосъемка с борта МКС зафиксировала признаки пульсационных изменений на языке ледника Колка в виде серии волн активизации» [Десинов, 2014]. 
Однако другие исследователи, в том числе изучившие те же материалы космофотосъемки, отрицают наличие волн активизации на леднике Колка в это время и дают этим признакам иное объяснение [Добрынин и др., 2003].

Но и наличие описанных Л.В. Десиновым [2004, 2014] признаков активизации ледника (в частности, выпуклый характер верхней части ледника) еще ничего не говорит о причинах его активизации, не исключает ее газодинамической (а не масс-балансовой) природы и не предопределяет характер дальнейшего протекания пульсации ледника.

16. «На следующий год после катастрофического выброса ледника геофизическими методами под его ложем был обнаружен очаг магмы с температурой около $1000{ }^{\circ} \mathrm{C}$. Наличие очага подтверждено и космическим зондированием в ИКдиапазоне спектра» [Десинов, 2014].

Сказанное (в приведенном Л.В. Десиновым его изложении) неточно и недостоверно.

Эти сведения согласуются с представлениями об эндогенной природе Колкинской катастрофы, но не указывают ни на конкретный ее характер (механизм протекания), ни на ее непосредственную причину (вызвавший ее природный фактор, действие которого обусловило и, соответственно, объясняет особенности ее протекания и результаты).

17. «Существенное увеличение воды в леднике и на его ложе под воздействием флюидных газов, внешней нагрузки и тепловых потоков» [Десинов, 2014].

В литературе, прежде всего, Л.В. Десиновым [Десинов, 2004 и др.], указываются и другие причины, которые, как предполагается, могли существенно увеличить обводненность ледника Колка и его ложа.

Все это, однако, не могло вызвать Колкинскую катастрофу, учитывая ее особенности, и не позволяет объяснить эти особенности.

В связи с этим приведение данного пункта в списке Л.В. Десинова ничего не дает для раскрытия характера, механизма протекания и причин Колкинской катастрофы и лишь подтверждает отмеченное в пп. 2 и 6 настойчивое стремление Л.В. Десинова, как и других отечественных гляциологов, приписать воде основную, решающую роль в этой катастрофе, что не имеет под собой никаких оснований и опровергается многими фактами, в том числе приведенными ниже в списке Л.В. Десинова (пп. 21, 23, 30-34, 36-39).

18. В этом пункте своего списка Л.В. Десинов, в дополнение к сказанному им в п. 9, приводит сведения о сейсмических событиях, произошедших 19 и 20 сентября 2002 г.

19. В этом пункте отмечается «сейсмическое событие, произошедшее на леднике 20 сентября 22.21.26 (GMT). На склоне с противоположной стороны от левого борта ледника Колка оно ощущалось людьми как содрогание гор, сопровождавшееся сильным гулом» [Десинов, 2014].

В более ранней работе [Десинов, 2004, с. 84] местонахождение людей, испытавших эти ощущения, описано несколько иначе - «примерно в двух километрах от ледника Колка и севернее от него, за гребнем левого борта ледника, примерно на одном уровне с его поверхностью».

Кроме того, с учетом указанного [Десинов, 2014] времени, это событие не могло произойти 20 сентября: 20 сентября в указанное время ледника Колка уже не было. Оно произошло в это время не 20, а 19 сентября, т. е. в 02.21.2620 сентября 
по местному (и московскому) времени, как было отмечено ранее [Десинов, 2004, с. 84 и с. 86 , рис. 9$]$.

Характер этого события, его результаты и их место в цепи событий на стадии подготовки Колкинской катастрофы рассмотрены в работе [Бергер, 2006в].

20. «По данным космической съемки, сделанной за 8 часов до катастрофы, отмечено, что вдоль тыловой зоны ледника возникла огромная трещина - разлом. Ледник получил крен вправо и возвысился на несколько десятков метров над гребнем левой береговой морены» [Десинов, 2014].

Л.В. Десинов, к сожалению, не обсуждает эти данные. Особенно интересным и важным представляется определение причины быстрого и значительного вспучивания поверхности северной части тыльной зоны ледника, установленного О.В. Тутубалиной с соавторами [Тутубалина и др., 2005, с. 70].

По предположению этих авторов [там же], такое вспучивание могло быть вызвано резким падением скоростей движения льда и ростом напряжений сжатия при приближении к левой береговой морене и малоподвижному льду в ходе, вероятно, начавшегося ускоренного движения льда по ложу ледника или по внутриледниковым плоскостям скольжения. Не исключено, однако, что такое вспучивание в той или иной мере могло быть вызвано предкатастрофическим динамическим воздействием на ледник высоконапорных глубинных поствулканических газов, мощный концентрированный прорыв которых в это время в районе ледника Колка документально зафиксирован [Рототаева и др., 2005, с. 140; и др.] (но не значится в списке Л.В. Десинова, хотя является установленным очень важным фактом).

21. «По данным космической съемки, сделанной за 8 часов до катастрофы, обнаружены 3 куполообразных возвышения в тыловой области ледника возле подножия склона, с которого обрушились горные породы и лед» [Десинов, 2014].

Наиболее правдоподобное объяснение данного факта также состоит в предкатастрофическом вспучивающем воздействии на ледник высоконапорных глубинных поствулканических газов.

22. «Катастрофическое высокоскоростное вытеснение ледника Колка из его ложа произошло 20 сентября 2002 г. около 20 часов 08 минут 30 секунд???» [Десинов, 2014].

Понятие «вытеснение ледника» не имеет научного определения. Не дает его и Л.В. Десинов. Это лишает смысла и делает невозможным оперирование данным понятием в науке, в частности, установление его времени. Подобная же ситуация существует и с широко используемым понятием «сход ледника», также не имеющим научного определения и, соответственно, не являющимся научным.

23. «После выброса ледника в его тыловой части обнажились источники фумарольных газов, которые с разной интенсивностью продуцировались на поверхность. Газовое облако время от времени окутывало все вместилище ледника от склона до склона. В слабой концентрации газ сохранялся еще год» [Десинов, 2014].

Сведения об источниках фумарольных газов естественно было бы ожидать в следующем пункте, но они приведены почему-то только в п. 38.

Эти факты очень важны для установления непосредственной причины Колкинской катастрофы, выявления вызвавшего ее действующего фактора («рабочего тела»).

24. «После выброса ледника на его ложе на протяжении нескольких сотен метров оставалась масса раздробленного льда толщиной до 10 м» [Десинов, 2014]. 
Этой картине полностью соответствует проведенная одним из авторов данной статьи еще на начальном этапе изучения Колкинской катастрофы идентификация ее геодинамического типа (в ее эпицентре) в качестве газодинамического выброса ледника.

25. «После выброса ледника на его ложе примерно в 300 м западнее устья речки Шау образовалась подковообразная плотина высотой от 20 до $60 \mathrm{M}$, состоящая из глыб льда и обломков горных пород. Наличие коренных пород в основании плотины не установлено... Плотина состоит из двух ступеней...» [Десинов, 2014].

Данный факт, совместно с приведенным ниже фактом 29, фиксирует типичные фрагменты кольцевого навала, образующегося по периферии воронки выброса [Бергер, 2012г].

26. «На откосе правой береговой морены против устья речки Шау сформировался характерный микрорельеф поверхности с ровной укладкой каменных глыб и небольших обломков. На крупных выступающих камнях остались глубокие эрозионные борозды» [Десинов, 2014].

Время и продолжительность формирования этого микрорельефа неизвестны. Во всяком случае для селевых (гляциально-селевых) отложений такие образования не характерны.

27. «К правой береговой морене, отделяющей ущелье ледника Колка и ледник Майли, перемещен массив слоистого льда» [Десинов, 2014].

Объяснить такое перемещение можно только огромным по мощности газодинамическим выбросом (отбросом) этого массива в ходе грандиозного по масштабам взрывоподобного газодинамического выброса ледника Колка.

28. «В нижней части морены, отделяющей ущелье ледника Колка и ледник Майли, возникли борозды глубиной до 1 м, направленные в сторону ледника Майли» [Десинов, 2014].

Возникновение этих борозд можно объяснить только очень мощным абразионным воздействием каменных и ледовых обломков в ходе газодинамического выброса ледника Колка.

29. «В тылу ледника остались две ступени, сложенные обломками горных пород и льда» [Десинов, 2014].

Это очень важный факт, однозначно свидетельствующий о центробежном разлете ледово-каменного материала при взрывоподобном газодинамическом выбросе ледника Колка, ни с каких иных позиций не объяснимый [Бергер, 2012г] и, соответственно, опровергающий гляциодинамические, селевые и все другие представления о Колкинской катастрофе, ее характере и причинах (см. также п. 25).

30. «На склонах левого борта ущелья ледника Колка ниже устья речки Шау остался след максимально высокого прохождения ледово-водно-каменной массы. Превышение этого следа над тальвегом ущелья - до 170 м» [Десинов, 2014].

В литературе известны и значительно более высокие оценки превышений следов движения продуктов разрушения ледника Колка над тальвегом ущелья.

Л.В. Десинов, к сожалению, не указывает, как эта масса там «проходила» и, вообще, как она там оказалась, как она на такую высоту залетела (и как было установлено присутствие в этой массе воды).

На самом же деле, это - след инерциального движения (разлета, метания, отброса, выброса) ледово-каменных продуктов взрывоподобного разрушения ледника Колка в результате испытанного им исключительно мощного газодинамического воздействия с нижнего (подледникового) полупространства. 
Сказанное относится и к приведенным ниже фактам 31 и 32 и ко всем другим так называемым «примазкам» и «заплескам», остатки и следы которых длительное время сохранялись в эпицентре катастрофы и в зоне транзита на склонах Колкинского и Геналдонского ущелий, в том числе на весьма значительной высоте.

31. «На правом склоне Геналдонской долины ниже ледника Майли остался «примазок» льда протяженностью около 1000 м» [Десинов, 2014].

32. «²Примазок ${ }^{2}$ льда длиной около 600 м остался после катастрофы на склоне над левой береговой мореной. Он превышает гребень морены на 60-100 м» [Десинов, 2014].

33. «Произошло механическое нарушение ската левой береговой морены» [Десинов, 2014].

Такое практически мгновенное механическое нарушение моренного ската могло произойти только в результате исключительно сильного взрывного или подобного ему ударного воздействия каменного материала и льда.

34. «Огромные порции льда в трех местах вытеснены во время схода ледника в краевую ложбину за левую береговую морену» [Десинов, 2014].

Поскольку Л.В. Десинов говорит не о забросе, а о неком вытеснении льда, то, в принципе, оно могло произойти различным образом, с помощью различных механизмов, под воздействием различных причин. Данный факт нисколько не противоречит представлениям о газодинамической природе Колкинской катастрофы («схода» ледника Колка).

35. «В каньоне остались валы донной морены» [Десинов, 2014].

Данный признак может быть гетерогенетичным, конвергентно совпадающим при различном характере «схода» ледника Колка и различных его причинах.

36. «Изотопный состав снега, льда и воды в 2003 году» [Десинов, 2014].

В данном случае речь идет, конечно, не об изотопном, а о химическом составе.

«Величина отношения $\mathrm{S} / \mathrm{Cl}$ - это показатель связи с глубинным флюидом. До катастрофы 2002 г. этот показатель нигде в долине р. Геналдон и на леднике Колка не превышал 0,7 мг/л» [Десинов, 2014].

Но этот показатель не измеряется в мг/л.

37. «Изотопный состав снега и льда в 2007 году» [Десинов, 2014].

И в данном случае речь идет, конечно, не об изотопном, а о химическом составе.

При текстовом изложении результатов анализов концентрация молибдена и рения во второй пробе завышена на порядок.

Не выдерживают критики и рассуждения Л.В. Десинова об «активном вулканизме на леднике Колка».

38. «Во время аэровизуального обследования ледника 24 сентября 2002 г. после выброса ледника Колка на обнаженном южном склоне в 10-15 м ниже бывшей поверхности тыловой области обнаружена фумарола, из которой извергался газ. Другие наблюдатели обнаружили вторую фумаролу, которая располагалась, по разным оценкам, в 400-600 м выше на склоне» [Десинов, 2014].

Это - очень важная информация, характеризующая источники огромного количества газов в данном районе в сентябре 2002 г., с которой полностью согласуются результаты недавнего специального рассмотрения этого круга вопросов [Бергер, 2012a].

39. «По субъективной оценке многих участников полевых исследований и вертолетных облетов ледника Колка, в первую неделю после катастрофы в газовом 
составе преобладали сернистый газ, углекислый газ и сероводород» [Десинов, 2014].

Эту информацию авторы оставляют без комментариев.

40. «После завершения катастрофы на поверхности отложенного на ложе и сплотившегося льда постепенно образовались холмы конической формы высотой до 1,5 м с центральным отверстием, в которое можно было свободно вставить ледоруб и шест длиной 2,5 м» [Десинов, 2014].

Речь, очевидно, идет о так называемых «муравьиных кучах». Этот интересный и важный вопрос заслуживает отдельного рассмотрения.

В дополнение к рассмотренным сорока пунктам своего списка Л.В. Десинов в этой же работе высказывает некоторые другие положения по Колкинской проблеме. Остановимся на них, используя принятую Л.В. Десиновым рубрикацию.

«Эффект шампанского». Данный вопрос подробно рассмотрен в работе [Бергер, 2010], в которой показана неустранимая внутренняя противоречивость и, соответственно, ложность объяснений механизма и причин катастрофы на леднике Колка и в Геналдонском ущелье на основе «эффекта шампанского».

«Главный вывод: Катастрофа на леднике Колка произошла не от удара сверху, а от взрывного воздействия снизу!» [Десинов, 2014].

Соответствующие представления и их подробное обоснование уже давно приведены в работах одного из авторов данной статьи [Бергер, 2003, 2004a, 6, 2006а, б, 2007 и др.].

Продолжая свой «главный вывод», Л.В. Десинов пишет: «Причиной обвала ледника стало наложение нескольких природных факторов: гидрологических, гляциологических, тектонических, сейсмических и вулканогенных» [Десинов, 2014].

В этом высказывании неправильно определены сущность (характер, геодинамический тип) и механизм протекания Колкинской катастрофы (как обвал ледника, тогда как это был взрывоподобный направленный газодинамический выброса ледника) и не указан вызвавший ее основной действующий фактор (ее основная причина) - динамическое воздействие на ледник огромного количества высоконапорных глубинных поствулканических газов, скопившихся под ледником.

Нельзя не обратить внимание на то, что в своих заключениях (иногда весьма категорических, но не всегда достаточно определенных и аргументированных) Л.В. Десинов избегает ссылок на опубликованные фактические материалы, основанные на инструментальных данных сейсмических наблюдений [Заалишвили, Мельков, 2008, 2012; Заалишвили, Харебов, 2008; Заалишвили и др., 2005, 2007; и др.]. Между тем, это касается очень важных вопросов Колкинской проблемы - времени и характера начального движения ледника Колка, скорости движения ледовокаменного материала и др. Высказывания же Л.В. Десинова по этим вопросам не имеют никакого эмпирического обоснования, совершенно голословны и несостоятельны.

Таким образом, судя по недавней публикации [Десинов, 2014], а также более ранней работе [Десинов, 2008], Л.В. Десинов в последнее время частично отходит от своих прежних необоснованных и ошибочных гляциодинамических характеристик катастрофы на леднике Колка и в Геналдонском ущелье 20 сентября 2002 г. [Десинов, 2004 и др.] и начинает постепенно приближаться к некоторому пониманию (в самых общих чертах и со значительными искажениями) и признанию того, что сразу после катастрофы, начиная с 2003-2004 гг., писал о характере 
и причинах Колкинской катастрофы один из авторов этой статьи [Бергер, 2003, 2004a, б и др.].

Приведенный Л.В. Десиновым список, кратко рассмотренный в данной работе, является, конечно, далеко не полным, во многом непоследовательным и противоречивым (прежде всего, в силу наличия в нем артефактов, в том числе лишенных основания предположительных умозаключений). Тем не менее, он содержит значительный массив информации, важной для понимания Колкинской катастрофы и доказательного определения объясняющих ее причин.

\section{Литература}

1. Бергер М.Г. О характере природной катастрофы 20 сентября 2002 г. на леднике Колка // Сборник научных трудов Северо-Осетинского отделения АН ВШ РФ. № 1 (I). Владикавказ: Терек, 2003. С. 16-17.

2. Бергер М.Г. Газодинамический выброс ледника Колка 20 сентября 2002 г. новое катастрофическое природное явление // Предупреждение опасных ситуаций в высокогорных районах: Тезисы докладов Международной конференции, г. Владикавказ, 23-26 июня 2004 г. Владикавказ: РЕМАРКО, 2004а. С. 4-5.

3. Бергер М.Г. Природа процессов автоколебательного развития пульсирующего ледника Колка // Устойчивое развитие горных территорий: проблемы и перспективы интеграции науки и образования: Материалы V Международной конференции 21-23 сентября 2004 г. Владикавказ: Терек, 2004б. С. 248-251.

4. Бергер М.Г. Природная катастрофа на леднике Колка 20 сентября 2002 года внезапный газодинамический выброс ледника // Предупреждение опасных ситуаций в высокогорных районах: Доклады Международной конференции. Владикавказ - Москва, 23-26 июня 2004 г. Владикавказ: Олимп, 2006а. С. 41-49.

5. Бергер М.Г. Газодинамический выброс ледника Колка 20 сентября 2002 г. // Вестник Владикавказского научного центра РАН и РСО-А. 2006б. № 2. С. 33-37.

6. Бергер М.Г. О событии на леднике Колка в 2 часа 21 минуту 20 сентября 2002 г. // Вестник Владикавказского научного центра РАН и РСО-А. 2006 в. Т. 6. №4. C. 37-39.

7. Бергер М.Г. Ледник Колка: Катастрофа 20 сентября 2002 года - внезапный газодинамический выброс ледника. М.: Изд-во ЛКИ, 2007. 248 с.

8. Бергер М.Г. О неустранимом противоречии в объяснении механизма и причин катастрофы на леднике Колка и в Геналдонском ущелье на основе «эффекта шампанского» // Вестник Владикавказского научного центра РАН и РСО-А. 2010. Т. 10. №4. C. 62-63.

9. Бергер М.Г. О некоторых расчетах количества поствулканических газов, необходимого для газодинамического выброса ледника Колка // Геология и геофизика Юга России. 2012а. № 1. С. 75-87.

10. Бергер М.Г. О воронке выброса ледника Колка // Геология и геофизика Юга России. 2012б. №2. С. 55-64.

11. Бергер М.Г. О причинах интенсификации обвалов на ледник Колка перед его катастрофическим выбросом 20 сентября 2002 года и некоторых количественных оценках величины этих обвалов // Геология и геофизика Юга России. 2012 в. №3. C. 65-90.

12. Бергер М.Г. О некоторых следах, оставшихся на месте ледника Колка, как показателях характера Колкинской катастрофы 2002 года // Геология и геофизика Юга России. 2012 г. № 4. С. 75-85. 
13. Десинов Л.В. Пульсация ледника Колка в 2002 году // Вестник Владикавказского научного центра РАН и РСО-А. 2004. Т. 4. № 3. С. 72-87.

14. Десинов Л.В. Фантазии и реалии в решении проблемы противодействия катастрофам в долине реки Геналдон // Опасные природные и техногенные геологические процессы на горных и предгорных территориях Северного Кавказа: Труды Международной научно-практической конференции. Владикавказ, 20-22 сентября 2007 г. - Владикавказ: ВНЦ РАН и РСО-А, 2008. С. 167-173.

15. Десинов Л.В. Главные особенности и механизм катастрофического выброса ледника Колка в 2002 году // Доклад на Всероссийской конференции «Геодинамика, вулканизм, сейсмичность и экзогенные геологические процессы природного и техногенного характера на Кавказе». Владикавказ, 1-3 октября 2014 г. Владикавказ, 2014.

16. Добрынин Д.В., Никитин М.Ю., Галушкин И.В. Дешифрирование структур и сравнительный анализ материалов по району ледника Колка. Отчет. М.-Владикавказ. 2003. 31 с.

17. Дробышев В.Н. Гляциальная катастрофа Северной Осетии 20 сентября 2002 года // Вестник Владикавказского научного центра РАН и РСО-А. 2012. Т. 12. №3. C. 20-36.

18. Заалишвили В.Б., Невская Н.И., Макиев В.Д., Мельков Д.А. Интерпретация инструментальных данных процесса схода ледника Колка 20 сентября 2002 года // Вестник Владикавказского научного центра РАН и РСО-А. 2005. Т. 5. №3. С. 43-54.

19. Заалишвили В.Б., Невская Н.И., Макиев В.Д., Мельков Д.А. Особенности процесса схода ледника Колка 20 сентября 2002 года по инструментальным данным // Геофизика XXI столетия: 2006 год. Сборник трудов Восьмых геофизических чтений им. В.В. Федынского (2-4 марта 2006 г., Москва). Тверь: ООО «Издательство ГЕРС», 2007. С. 191-199.

20. Заалишвили В.Б., Мельков Д.А. Особенности движения ледово-каменной массы 20 сентября 2002 г. по сейсмологическим и геоморфологическим данным // Опасные природные и техногенные геологические процессы на горных и предгорных территориях Северного Кавказа: Труды Международной научно-практической конференции. Владикавказ, 20-22 сентября 2007 г. Владикавказ: ВНЦ РАН и PCO-A, 2008. C. 185-195.

21. Заалишвили В.Б., Мельков Д.А. Особенности процесса схода ледника Колка 20 сентября 2002 г. и его макросейсмическое проявление по инструментальным данным современных регистрационных систем // Геология и геофизика Юга России. 2012. №3. С. 29-44.

22. Заалишвили В.Б., Харебов К.С. Исследование процесса схода ледника Колка 20 сентября 2002 года по динамическим характеристикам инструментальных записей // Опасные природные и техногенные геологические процессы на горных и предгорных территориях Северного Кавказа: Труды Международной научнопрактической конференции. Владикавказ, 20-22 сентября 2007 г. Владикавказ: ВНЦ РАН и РСО-А, 2008. С. 202-221.

23. Ледник Колка: вчера, сегодня, завтра / [отв. ред. акад. Ю.Г. Леонов, В.Б. Заалишвили]; Центр геофиз. исследований Владикавказ. науч. центра РАН и РСО-А. Владикавказ, 2014. 429 с. 
24. Процесс схода ледника Колка 20 сентября 2002 г. / Отв. ред. В.Б. Заалишвили. Владикавказ: ВНЦ РАН и РСО-А, 2009. 165 с.

25. Рототаев К.П., Ходаков В.Г., Кренке А.Н. Исследование пульсирующего ледника Колка. М.: Наука, 1983. 169 с.

26. Рототаева О.В., Котляков В.М., Носенко Г.А., Хмелевской И.Ф., Чернов Р.А. Исторические данные о подвижках ледников на Северном Кавказе и Кармадонская катастрофа 2002 г. // Материалы гляциологических исследований. 2005. Вып. 98. С. 136-145.

27. Тутубалина О.В., Черноморец С.С., Петраков Д.А. Ледник Колка перед катастрофой 2002 года: новые данные // Криосфера Земли. 2005. Т. IX. №4. С. 62-71.

28. Файф У., Прайс Н., Томпсон А. Флюиды в земной коре. М.: Мир, 1981. $436 \mathrm{c}$.

29. Черноморец С.С. Селевые очаги до и после катастроф. М.: Научный мир, 2005. 184 c.

DOI: 10.23671/VNC.2014.4.55487

ON THE EVOLUTION AND THE CONTEMPORARY STATE OF THE IDEAS OF SOME GLACIOLOGISTS ABOUT THE CATASTROPHE ON THE GLACIER KOLKA AND IN THE GENALDON GORGE ON SEPTEMBER 20, 2002. L. V. DESINOV LIST: FACTS AND THE ARTIFACTS

(c) 2014 M.G. Berger,1,2, geol.-min. sci. doct., prof.; V.B. Zaalishvili², phys.-math. sci. doct., prof.

${ }^{1}$ North-Caucasian innovation center «Steady development of mountain territories»;

${ }^{2}$ Center of Geophysical Investigation VSC RAS \& RNO-A, 93a, Markov st.,

Vladikavkaz, 362002, Russia. e-mail: berger7@ rambler.ru; cgi_ras@mail.ru.

The list of L.V. Desinov is examined., which contains, on its assertion, the enumeration of the facts, which characterize catastrophe on the glacier Kolka and in Tthe genaldon gorge on September 20, 2002. Brief commentaries to these facts are given. Essential (but only partial) transformation and contemporary state of L.V. Desinov ideas about the nature and the reasons For kolkinskoy catastrophe are shown, is given estimation of their validity.

Keywords: Glacier Kolka, catastrophe 2002, facts, the artifacts. 